\title{
Self-reported chair-rise ability relates to stair-climbing readiness of total knee arthroplasty patients: A pilot study
}

\author{
John Nyland, PT, EdD, SCS, ATC, FACSM; ${ }^{1 *}$ Karen Frost, PhD ${ }^{2}$ Peter Quesada, PhD ${ }^{3}$ Claudia Angeli, PhD; ${ }^{4}$ \\ Ann Swank, PhD; ${ }^{5}$ Robert Topp, PhD, RN; ${ }^{2}$ Art L. Malkani, MD $^{1}$ \\ ${ }^{1}$ Department of Orthopaedic Surgery, ${ }^{2}$ School of Nursing, and ${ }^{3}$ Speed School of Engineering, University of Louisville, \\ Louisville, KY; ${ }^{4}$ Frazier Rehabilitation Institute, Louisville, KY; ${ }^{5}$ Department of Health and Sport Sciences, University \\ of Louisville, Louisville, KY
}

\begin{abstract}
Following total knee arthroplasty (TKA), physical therapists must evaluate patient readiness to safely begin stairclimbing. Physical therapists might find self-reported chair-rise ability useful in determining stair-climbing readiness of patients. We grouped 31 subjects who were at approximately 3.6 weeks post-TKA by chair-rise ability (group 1 = "Because of my knee, I can only rise from a chair if I use my hands and arms to assist," group 2 = "I have pain when rising from the seated position, but it does not affect my ability to rise from the seated position," and group 3 = "My knee does not affect my ability to rise from a chair"). Next, we determined time of stair-climbing ascent and descent, number of chair rises in 30 seconds, isokinetic quadriceps femoris and hamstring muscle group strength, and self-reported knee function survey scores. Groups 3 and 2 descended stairs more quickly than group 1; group 3 displayed greater involved and noninvolved knee extensor torque per body weight than group 1 or 2 and had superior self-reported knee function scores than group 1. Patient perception of chair-rise ability at approximately 3.6 weeks post-TKA is useful in helping physical therapists determine patient readiness to safely begin stair-climbing.
\end{abstract}

Key words: arthroplasty, function, home-based care, isokinetics, knee, osteoarthritis, patient outcomes, quadriceps femoris, rehabilitation, stair-climbing, TKA.

\section{INTRODUCTION}

Safely ascending and descending stairs are essential activities of daily living (ADL) that are often difficult for a patient with knee osteoarthritis [1-3]. Although total knee arthroplasty (TKA) is generally successful in reducing osteoarthritic knee pain and patients identify pain relief as the main reason for undergoing TKA [1], many patients' ability to perform functional activities such as stair-climbing remain limited for an extended time following TKA compared with age-matched individuals who are nondisabled [4].

Patients increasingly expect advances in TKA surgical techniques and implant designs to enable them to return to their original functional status without pain or impairment [5]. In a survey study of 253 patients at a minimum of 1 year following primarily unilateral TKA (mean age $=68.1$, range $=23-90$ years), Noble et al. reported that 83 percent of satisfied patients never or rarely took pain medication for surgical knee pain compared with 65 percent of dissatisfied patients [6]. Dissatisfied patients also reported at least some difficulty

\footnotetext{
Abbreviations: $\mathrm{ADL}=$ activities of daily living, $\mathrm{BMI}=$ body mass index, BW = body weight, KOS-ADLS = Knee Outcome Survey-Activity of Daily Living Scale, PT = physical therapy, TKA = total knee arthroplasty.

* Address all correspondence to John Nyland, PT, EdD, SCS, ATC, FACSM; Division of Sports Medicine, Department of Orthopaedic Surgery, University of Louisville, 210 East Gray St, Suite 1003, Louisville, KY 40202; 502-852-2782; fax: 502-852-7227. Email: john.nyland@louisville.edu DOI: 10.1682/JRRD.2006.11.0146
} 
performing 71 percent of ADL, including stair-climbing, compared with only 45 percent of the satisfied patients. Pain relief appears to be directly related to patient satisfaction following TKA; however, their inability to perform ADL such as stair-climbing contributes largely to their level of dissatisfaction. Trousdale et al. [7], in studying patient (mean age $=70$, range $=37-89$ years) concerns before TKA surgery, reported that after ranking restoration of the ability to walk as much as they wished as the first most important concern, patients ranked the ability to go up and down stairs as the second [7].

Pain and insufficient lower-limb muscle strength, particularly at the quadriceps femoris muscle group, may contribute to a patient's increased falling risk during level walking and stair-climbing [8-10]. Falling increases the likelihood that patients might sustain additional and potentially life-threatening injuries (closed head injury, fractures, etc.) that might further increase their disability level, reduce quality of life, prolong rehabilitation, and promote a general health decline associated with the inactivity of protracted bed rest $[1,4]$. Falls in public places mostly occur on steps and almost 80 percent of these occur during stair descent [11-14]. During stair ascent, the forward momentum of a fall is arrested by the stair structure itself, whereas during stair descent, the distance to fall is potentially much greater [11].

An essential part of contemporary physical therapy (PT) is preventing further injury or minimizing the effects of chronic conditions that might contribute to increased disability and decreased functional independence [15]. Physical therapists must routinely determine a patient's readiness to perform functional tasks such as stair-climbing [14]. Although self-reported knee function surveys generally ask patients to rate their perceived ability to ascend or descend stairs, many patients have only attempted this task on 1 to 3 steps as a hospital inpatient with help in the PT clinic or upon entering their home when returning from the hospital. From these limited recent experiences, they may have difficulty accurately appraising their stair-climbing readiness and the level of assistance they truly require. Additionally, although quadriceps femoris muscle group weakness contributes to fall risk, performing post-TKA appraisal of the strength of this muscle group and its function during stair-climbing can be difficult because of concerns regarding patient pain levels and safety, surgical incision status, and prosthesis integrity.
Particularly for the home care physical therapist who often has no additional assistance, identifying a simple and safe method for determining patient readiness to safely begin stair-climbing during early postoperative rehabilitation would be useful. A therapist may find that patients' perception of their ability to perform an independent chair rise, which they have attempted multiple times following surgery while hospitalized, in the clinic, and at home, may be a practical way to estimate patient readiness to safely begin stair-climbing activities. Several reports have related chair-rise performance to knee extensor muscle-force-generating ability [16-20]. Tasks such as the chair rise have minimal injury risk if not performed correctly, while unsafe stair-climbing has comparatively greater injury risk, particularly when patients initially attempt stair descent.

This retrospective, posttest design study evaluated the usefulness of self-reported chair-rise ability ratings for determining patient readiness to begin safe stair-climbing. Timed stair-climbing tests have been used extensively among patient groups who have lower-limb osteoarthritis or who have undergone total joint replacement [21-24]. In a prospective observational study of 83 patients following TKA (aged $60.3 \pm 11.2$ [values are mean \pm standard deviation unless expressed otherwise]), Kennedy et al. demonstrated a progressive postoperative pattern of recovery in timed stair-test performance over 15 weeks of study [21]. Sowers et al. reported that timed stair-test performance is directly related to functional quadriceps femoris muscle group strength and knee pain among women with knee osteoarthritis (aged $46.9 \pm 4.6$ ) during weightbearing functional tasks with prolonged stair ascent and descent times and more time spent in double support [22]. Perron et al. reported that timed stair-test performance correlated strongly with the time needed for women (aged $65.6 \pm 6.0$ ) who had undergone total hip arthroplasty to walk $10 \mathrm{~m}$ on a level surface and to stand up from a chair and walk $3 \mathrm{~m}$ compared with nondisabled age-matched subjects [23]. In another study that reported timed stairtest performance, Mizner et al. tested 22 male and 18 female subjects aged $64 \pm 9$ before surgery and at 1, 2, 3, and 6 months following unilateral TKA [24]. They found that timed stair-test performance displayed fair-to-moderate inverse relationships with involved and noninvolved lower-limb isometric quadriceps femoris muscle group strength. Our hypothesis was that individuals who perceived their chair-rise ability as poor would also display poor stair-climbing ability and weaker quadriceps femoris 
muscle group strength. To determine actual chair-rise and stair-climbing ability, we collected data that included a patient self-report of perceived knee function during ADL, bilateral isokinetic knee extensor and flexor torque (to determine quadriceps femoris and hamstring muscle group strength), a 30-second chair-rise test, and a timed stair test. Information regarding patient perceived chairrise ability was obtained from the self-reported knee function survey.

\section{MATERIALS AND METHODS}

\section{Subjects}

Study procedures were approved by a medical institutional review board, and subjects provided written informed consent. A total of 31 consecutive subjects (22 females, 9 males), aged $63 \pm 6.4$, with body mass index (BMI) of $31.4 \pm 6.8$, height $169.1 \pm 10.8 \mathrm{~cm}$, and weight $90.4 \pm 22.8 \mathrm{~kg}$, who were scheduled to undergo TKA for unilateral knee osteoarthritis agreed to participate in this study. Of these subjects, 16 (51.6\%) were also being treated for hypertension, 15 (48.4\%) had documented grade II to IV knee osteoarthritis at the contralateral knee, and 7 (27.6\%) had a history of degenerative low back conditions (5 had chronic disc disease, 2 had spondylosis). No subjects had upper-limb dysfunction.

\section{Surgery}

All subjects underwent unilateral TKA with femoral, tibial, and patellar button components performed by the same fellowship trained surgeon (ALM). Twenty subjects received the Osteonics Knee System (Stryker Corp, Kalamazoo, Michigan), and eleven subjects received the MIS $^{\mathrm{TM}}$ Total Knee Arthroplasty System (Zimmer Inc, Warsaw, Indiana). Total tourniquet time was $50 \pm 10$ minutes. All subjects received comparable inpatient nursing and PT care.

\section{Rehabilitation}

All subjects participated in a progressive home-based therapeutic exercise program that was initiated 3 to 4 days postsurgery. Exercises included quadriceps setting, shortarc knee extensions, four-way straight-leg raises, seated knee flexion, supine "wall slide" knee flexion, partial range-of-motion squats, standing-end range knee extension (with progressive elastic-band resistance), standing calf raises, and more functional tasks such as multidirec- tional step-ups on a 2-inch-tall $(5.1 \mathrm{~cm})$ step, and progressive stair ascent and descent as tolerated with physical therapist assistance. Twenty subjects performed additional standing hip extension, seated leg-pressing and knee flexion exercises with elastic-band resistance, and combined partial squatting with resisted hip adduction against a 12inch-diameter $(30.5 \mathrm{~cm})$ therapy ball in addition to more functional tasks such as step-ups on a 4-inch $(10.2 \mathrm{~cm})$ step, lateral shuffle stepping with elastic-band resistance, and single lower-limb standing balance exercises. Subjects received $9.2 \pm 3.6$ total home PT treatment sessions over $3.6 \pm 0.7$ weeks following surgery. All subject data were collected between 3 and 4 weeks post-TKA at an outpatient PT center.

\section{Survey}

Subjects completed the Knee Outcome SurveyActivity of Daily Living Scale (KOS-ADLS). The KOSADLS is a 14-item questionnaire that assesses common knee symptoms and functional limitations during ADL. Items are scored on a Likert-type scale based on perceived function ability level. Functional limitations are evaluated with eight items relating to a person's ability to perform specified tasks such as walking, stair-climbing, and rising from a chair. An overall score between 0 and 100 percent is generated, with a higher number reflecting better patient function. The validity of this scale has been demonstrated by moderately strong levels of correlation $(r>0.60)$ with the Lysholm Knee Scale and the Global Rating of Knee Function [25]. In addition, this scale displays a high level of internal consistency, test-retest reliability, and a more precise knee function measurement than can be obtained with the Lysholm Knee Scale [25].

Subjects were grouped based on their response to the following KOS-ADLS question: "How does your knee affect your ability to rise from a chair?” Response options for this question were-

1. "Because of my knee, I cannot rise from a chair."

2. "Because of my knee, I can only rise from a chair if I use my hands and arms to assist."

3. "I have pain when rising from the seated position, but it does not affect my ability to rise from the seated position."

4. "My knee does not affect my ability to rise from a chair." 
JRRD, Volume 44, Number 5, 2007

\section{Function Testing}

\section{0-Second Chair-Rise Test}

We initiated the 30-second chair-rise test with subjects seated in a firm chair that had no arms. During test performance, subjects were instructed to assume an upright standing posture and then to return to the seated starting position as many times as possible within 30 seconds. With the subjects' first movement, we timed the test using a handheld stopwatch. This assessment has demonstrated high validity for quadriceps femoris muscle group strength by correlating with single-repetition maximum leg-press ability, and it has also shown high test-retest reliability ( $r=$ 0.89) [26-27]. The same tester performed all measurements, and a researcher was positioned near test subjects to assist if needed.

\section{Timed Stair Test}

Subjects were also timed with a handheld stopwatch as they ascended and then descended a flight of ten 7-inch $(17.8 \mathrm{~cm})$ tall steps with an 11-inch $(27.9 \mathrm{~cm})$ tread depth. While facing the first step at no more than 1 foot $(30.5 \mathrm{~cm})$ away and with their hands by their sides, subjects were instructed to ascend the steps as quickly as possible without compromising safety. Following a 30 -second rest period at the top of the steps, subjects were instructed to descend the steps as quickly as possible without compromising safety. We allowed subjects to use one hand rail during each phase if required. Each test phase ended when both of the subject's feet reached the top or bottom of the staircase, respectively. The same investigator performed all test measurements, and pilot testing before data collection demonstrated excellent test-retest measurement reliability $(r=0.94)$. A researcher was positioned near subjects during testing to assist if needed. The timed stair test has been widely reported as an evaluation method for determining stair-climbing proficiency among patients with knee osteoarthritis, post-TKA or post-total hip arthroplasty [21-24,28].

\section{Isokinetic Knee Strength}

We assessed bilateral knee extensor and flexor torque using an isokinetic dynamometer (Biodex, Shirley, New York) at $60^{\circ} / \mathrm{s}$ and a range of motion between $110^{\circ}$ and $5^{\circ}$ knee flexion using standard techniques including calibration. We measured subject active knee extension and flexion using a handheld goniometer before isokinetic testing. Subjects performed three submaximal warm-up repeti- tions before performing three maximal effort repetitions with a 10-second rest period between each repetition. Mean peak isokinetic knee extensor and flexor torque was determined and was standardized to body weight (BW).

\section{Statistical Analysis}

Kolmogorov-Smirnov tests revealed normal data distributions, so we performed parametric statistical analysis. We used a multivariate, general linear model analysis of variance for main effects with the independent variable of perceived chair-rise ability group to compare dependent variables, including physical performance tests (stair ascent and descent time, isokinetic knee extensor torque per BW) and the KOS-ADLS score. To evaluate the relationship between mean peak isokinetic knee extensor torque and stair-climbing variables that displayed significant group differences, we used Pearson product moment correlations. In addition, we selected an alpha level of $p<$ 0.05 to indicate statistical significance with Bonferroni adjustments for multiple comparisons $(0.05 / 5=0.01)$ and used Tukey honest significant difference post hoc tests to delineate the specific location of group differences.

\section{RESULTS}

No study participant selected the self-reported chairrise response option, "Because of my knee, I cannot rise from a chair." Twelve subjects responded, "Because of my knee, I can only rise from a chair if I use my hands and arms to assist" (group 1). Twelve subjects responded, "I have pain when rising from the seated position, but it does not affect my ability to rise from the seated position" (group 2). Seven subjects responded, "My knee does not affect my ability to rise from a chair" (group 3). Groups did not display statistically significant differences for the proportion of subjects who performed additional therapeutic exercises (Fisher exact test $=0.83, p=0.79$ ), for the proportion of subjects who had contralateral knee osteoarthritis (Fisher exact test $=0.23, p=0.97$ ), hypertension (Fishers exact text $=0.54, p=0.90$ ), or degenerative low back conditions (Fisher exact test $=0.24, p=0.99$ ). Subject demographic characteristics based on self-reported chair-rise ability group are displayed in Table 1.

Groups displayed a similar percentage of women and men except for group 3, which had 57.1 percent (four of seven) men. With a greater proportion of men, group 3 subjects were also taller on average compared with the 
other groups. Group 3 subjects displayed greater mean involved and noninvolved knee flexor torque per BW and on average performed more sit-to-stand repetitions in 30 seconds than group 1 and 2 subjects. On average, group 1 subjects had greater BW and BMI scores than group 2 or 3 subjects. At the time of testing, groups had received a similar number of weeks of home PT treatment; however, group 2 subjects received an average of 3.0 and 2.2 less total home PT treatment sessions than groups 1 and 3 subjects, respectively.

All subjects completed each test component without assistance. Group 3 subjects (8.3 \pm 3.0 s) ascended stairs more quickly than group 1 (19.6 $\pm 12.7 \mathrm{~s})$ and group 2 (11.3 \pm 4.9 s) subjects; however, these differences were not statistically significant $(p=0.02)$. Groups differed for stair descent time, involved and noninvolved mean peak knee extensor torque per BW, and KOS-ADLS score (Table 2). Tukey post hoc tests revealed that group 3 and group 2 subjects descended stairs more quickly than group 1 subjects, group 3 subjects displayed greater involved and noninvolved mean peak isokinetic knee extensor torque per BW than groups 1 and 2 subjects, and group 3 subjects displayed higher KOS-ADLS scores than group 1 subjects (Table 3 ). Pearson product moment correlations revealed moderate inverse relationships between noninvolved $(r=-0.62)$ and involved $(r=-0.70)$ mean peak isokinetic knee extensor torque per BW and stair descent time, explaining 38 and 49 percent of the variability of timed stair descent performance, respectively (Figure).

Table 1.

Mean \pm standard deviation values of chair-rise group demographic characteristics with subjects grouped by response.

\begin{tabular}{|c|c|c|c|}
\hline Variable & Group 1* & Group $2^{\dagger}$ & Group $3^{\ddagger}$ \\
\hline \multicolumn{4}{|l|}{ Sex } \\
\hline Females $(n)$ & 10 & 9 & 3 \\
\hline Age (yr) & $63.6 \pm 5.6$ & $62.0 \pm 7.0$ & $65.1 \pm 6.5$ \\
\hline Height (cm) & $165.4 \pm 7.4$ & $169.0 \pm 13.0$ & $174.9 \pm 11.2$ \\
\hline Involved Knee Flexor Torque/BW (N•m/kg) & $0.20 \pm 0.18$ & $0.21 \pm 0.12$ & $0.37 \pm 0.11$ \\
\hline Noninvolved Knee Flexor Torque/BW (N•m/kg) & $0.35 \pm 0.22$ & $0.40 \pm 0.22$ & $0.56 \pm 0.14$ \\
\hline Sit-to-Stand (reps) & $9.0 \pm 1.9$ & $11.3 \pm 3.7$ & $14.4 \pm 6.2$ \\
\hline Body Mass Index & $35.9 \pm 7.5$ & $27.9 \pm 5.2$ & $29.4 \pm 3.1$ \\
\hline
\end{tabular}

Table 2.

Multivariate general linear model analysis of variance (between group main effects).

\begin{tabular}{|c|c|c|c|c|c|c|}
\hline Dependent Variable & $\begin{array}{c}\text { Type III } \\
\text { Sum of Squares }\end{array}$ & $d f$ & $\begin{array}{c}\text { Mean } \\
\text { Square }\end{array}$ & $\begin{array}{c}F \\
\text { Statistic }\end{array}$ & $p$-Value & Power \\
\hline Stair Ascent (s) & 681.1 & 2 & 340.6 & 4.6 & 0.02 & 0.73 \\
\hline Stair Descent (s) & $1,046.8$ & 2 & 523.4 & 8.2 & $0.002^{*}$ & 0.94 \\
\hline Involved Knee Extensor Torque/BW (N•m/kg) & 0.5 & 2 & 0.3 & 6.4 & $0.005^{*}$ & 0.87 \\
\hline Noninvolved Knee Extensor Torque/BW (N•m/kg) & 1.7 & 2 & 0.9 & 9.1 & $0.001^{*}$ & 0.96 \\
\hline KOS-ADLS (score) & $1,530.3$ & 2 & 765.2 & 6.4 & $0.005^{*}$ & 0.87 \\
\hline
\end{tabular}

${ }^{*} p \leq 0.01$ (Bonferroni adjustment for multiple comparisons).

BW = body weight, $d f=$ degrees of freedom, KOS-ADLS = Knee Outcome Survey-Activity of Daily Living Scale. 
Table 3.

Tukey post hoc test results (mean \pm standard deviation) by chair-rise group.

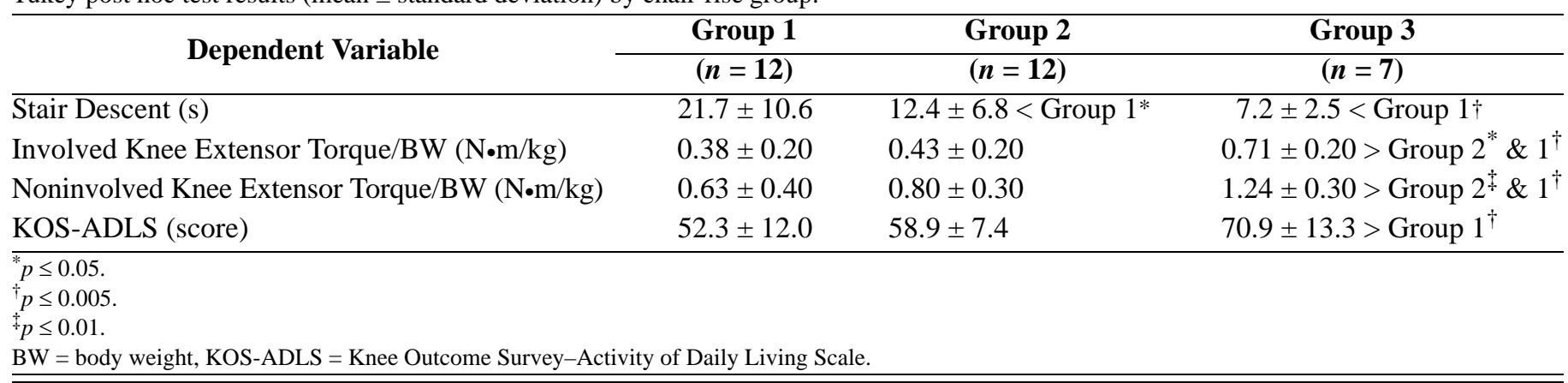

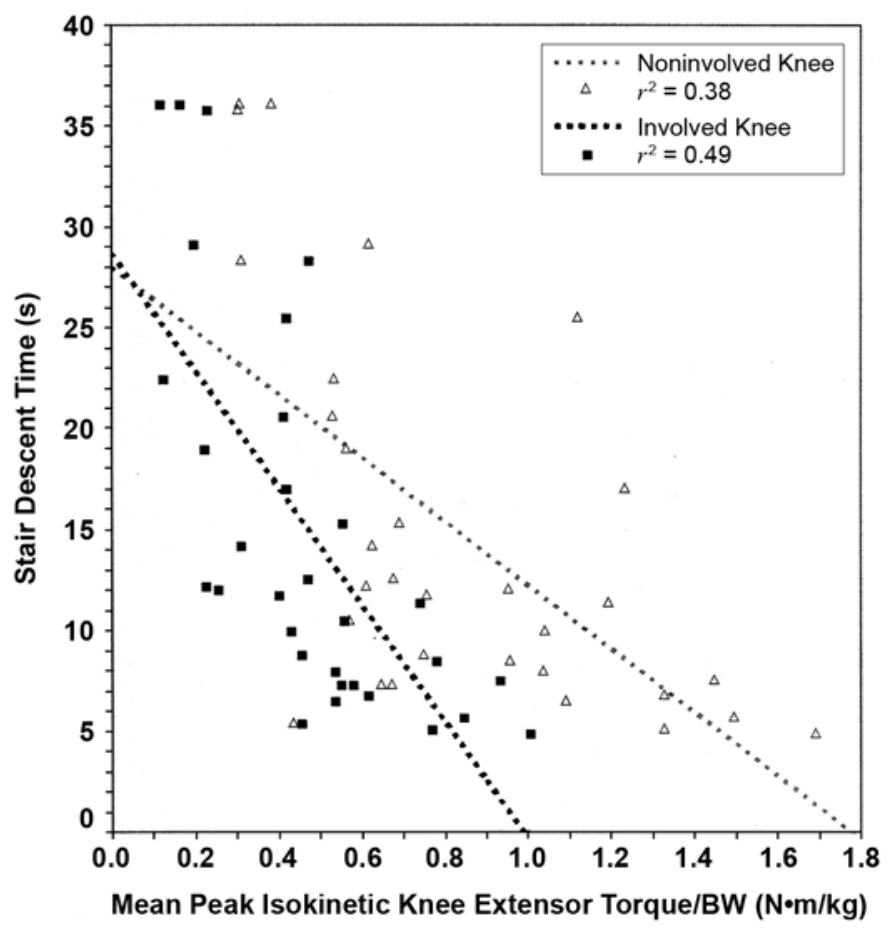

Figure.

Pearson product moment correlations showing variability between noninvolved $(r=-0.62)$ and involved $(r=-0.70)$ mean peak isokinetic knee extensor torque/BW and stair descent time, explaining approximately $38 \%$ and $49 \%$ of variability $\left(r^{2}\right)$ of timed stair descent performance, respectively. $\mathrm{BW}=$ body weight.

\section{DISCUSSION}

Subjects who reported that their knee did not affect their ability to chair rise (group 3) and subjects who reported knee pain when rising from the seated position but believed that it did not affect their ability to rise from a seated position (group 2) were able to descend stairs more quickly without compromising safety than subjects who reported that because of their knee, they could only chair rise if they used their hands and arms to assist (group 1). This suggests that group 3 subjects need less home-based PT to assist with stair-climbing. Group 3 subjects also displayed greater involved and noninvolved side mean peak isokinetic knee extensor torque per BW than group 2 and group 1 subjects. Additionally, the mean peak isokinetic knee extensor torque per BW that they displayed at their noninvolved lower limb almost matched Ikezoe's reported $1.28 \mathrm{~N} \cdot \mathrm{m} / \mathrm{kg}$ discriminating criterion for identifying older women (aged $75.3 \pm 3.4$ ) who had a decreased fall risk [29]. The moderate inverse relationship that was observed between involved and noninvolved mean peak isokinetic knee extensor torque and stair descent supports the association between quadriceps femoris muscle group strength and the eccentric activation required to control the vertical momentum of the body during stair descent $[11,22,24]$. This finding reinforces the close relationship between quadriceps femoris muscle group strength and the patients' ability to safely descend stairs during the initial 3 to 4 weeks following TKA [22,24].

Since knee joint loading is related to body mass and biomechanical stresses are magnified by increased body mass, subjects who weigh more or have a higher BMI are more likely to have difficulty performing weight-bearing functional activities or therapeutic exercises without compensatory contralateral lower- and/or upper-limb use following TKA [30-31]. This is particularly true if the quadriceps femoris muscle group is appreciably weak before surgery. In our study, subjects who reported that because of their knee, they could only chair rise if they used their hands and arms to assist (group 1) had a higher mean BMI and BW than the other groups. Kaufman et al. reported that as the BMI 
increased for both women and men with knee osteoarthritis [32], either internal knee extensor moments across all gait conditions (level walking, stair ascent, and stair descent) decreased to reduce knee joint loads or maladaptive gait compensations were used, such as excessively loading the contralateral lower limb, leaning away from the involved lower limb, or using the upper limbs in a manner that might increase the fall risk [32]. Additionally, women with knee osteoarthritis had significantly greater internal knee extensor moments than men, suggesting that overweight women with knee osteoarthritis might have greater difficulty performing weight-bearing functional tasks such as stair-climbing than men. This finding may partially explain why groups 1 and 2, with their greater proportion of women, did not perform as well in our study.

At 3 to 4 weeks following TKA, our subjects had inadequate time to maximize function. Testing at this time however is relevant to concerns related to stair-climbing training. Therapeutic exercise programs generally transition from more non-weight-bearing, isolated single-joint exercises to more functionally relevant weight-bearing activities. Personnel and equipment resources at an outpatient PT center may enable a greater focus on task-specific functional training including stair-climbing. Skeletal muscle-force production is highest during negative muscle work (an eccentric activation) when an activated muscle is lengthened by an external load such as during stair descent [33]. The specificity of exercise theory suggests that the therapeutic exercise program should target eccentric lowerlimb muscle strength; however, as mentioned earlier, concerns over patient pain levels and safety, surgical incision status, and prosthesis integrity usually limit early eccentric strength-training intervention. In addition to the quadriceps femoris muscle group, therapeutic exercises should also address hip abductor/adductor muscle strength and incorporate incrementally greater step heights to improve dynamic lower-limb joint stability [34]. This addition may be especially important for shorter subjects and those with greater BMI or BW levels such as group 1 subjects in this study. In a randomized, blinded, prospective clinical trial evaluating 15 subjects (aged 62-85) who had at least one lower-limb impairment, Krebs et al. reported that subjects $(n=9)$ who participated in a functional training program demonstrated a more effective anterior-to-vertical momentum transfer strategy by displaying greater internal knee extensor torque during chair-rise performance compared with subjects $(n=6)$ who trained using conventional strength-training exercises [35].
Groups 1 and 2 that did not perform as well in our study had a greater percentage of women, had a greater BMI or BW, were shorter, and had weaker quadriceps femoris muscle group strength at both the involved and noninvolved lower limb. These subjects also had weaker hamstring muscle group strength, which suggests that they were less able to rely on this muscle group as a hip extensor to assist with dynamic hip and knee postural stability. Interestingly, age did not differ significantly between groups, which suggests a lesser effect for chronological age compared with other health factors.

At 3 to 4 weeks following unilateral TKA for knee osteoarthritis, group 3 subjects who reported that their knee did not affect their ability to chair rise displayed lower stair descent times and had greater bilateral mean peak isokinetic knee extensor torque and KOS-ADLS scores than group 1 subjects who reported that because of their knee, they could only chair-rise if they used their hands or arms to assist. More importantly, group 3 subjects could descend stairs more quickly than group 1 subjects without compromising safety. This finding suggests that patient selfreported chair-rise ability at 3 to 4 weeks post-TKA can help the home physical therapist decide whether or not a patient is ready to safely attempt stair-climbing. Group 3 subjects are more likely to be able to safely stair-climb and to require less PT intervention to achieve stair-climbingrelated treatment plan goals. These subjects may also be ready for more advanced functional weight-bearing exercises than group 2 or 1 subjects. Therefore, the physical therapist should feel more confident having these individuals perform weight-bearing functional activities and therapeutic exercises to better address treatment plan goals related to neuromuscular and cardiovascular conditioning in addition to merely training to achieve independent stairclimbing. Group 1 patients are not ready for independent stair-climbing and warrant greater PT focus on pain control in addition to lower-limb and perhaps even upper-limb strengthening exercises. On average, group 1 subjects received more physical therapist visits and sessions; however, these home sessions provided by a solo physical therapist may have benefited patients less than more focused PT intervention at an outpatient PT center where personnel and equipment resources are more available.

Group 2 subjects may be the target population for home-based PT intervention [36-37]. PT intervention that identifies and treats the specific causes of pain that these individuals experience when performing a chair rise may also help decrease pain that they experience when climbing 
stairs. Although TKA alone generally alleviates a considerable portion of the pain associated with knee osteoarthritis [38], pain from the recent surgery may still be present. Additionally, in contrast to pain control alone, restoring functional independence with ADL requires considerably more patient effort and compliance with an appropriately designed therapeutic exercise program to improve stair-climbing as well as maintain or improve general health, including BW reduction if needed [39].

This study is limited in that it was retrospective; it had a design of a posttest study only and a small number of subjects. Although having the same surgeon perform all surgeries and the same PT agency provide all home PT sessions fostered relatively consistent interventions, these results may not generalize to other patient groups. We did not include kinematic and kinetic data in this analysis or perform electromyography. Although measurements such as these are important to verify group differences, physical therapists do not routinely have access to this equipment, particularly when they provide homebased care. Further study with a larger sample size that includes these measurements is needed to verify group differences for knee moment, trunk and lower-limb kinematic, and muscle-activation timing differences.

\section{CONCLUSIONS}

Groups 3 and 2 descended stairs more quickly than group 1, and group 3 displayed greater involved and noninvolved knee extensor torque per BW than group 1 or 2 and had superior self-reported knee function scores than group 1. Patient perception of chair-rise ability at approximately 3.6 weeks post-TKA is useful in helping physical therapists determine patient readiness to safely begin stair-climbing.

\section{ACKNOWLEDGMENTS}

We thank the physical therapists at the Visiting Nurses Association of Louisville, Kentucky, for performing all home-based PT interventions.

This material is the result of work supported with resources and use of facilities at the University of Louisville under the Intramural Multidisciplinary Research Grants Program.
The authors have declared that no competing interests exist.

\section{REFERENCES}

1. Mizner RL, Petterson SC, Stevens JE, Axe MJ, SnyderMackler L. Preoperative quadriceps strength predicts functional ability one year after total knee arthroplasty. J Rheumatol. 2005;32(8):1533-39. [PMID: 16078331]

2. Davis MA, Ettinger WH, Nehaus JM, Mallon KP. Knee osteoarthritis and physical functioning: evidence from the NHANES I Epidemiologic Followup Study. J Rheumatol. 1991;18(4):591-98. [PMID: 2066950$]$

3. Guccione AA, Felson DT, Anderson JJ, Anthony JM, Zhang Y, Wilson PW, Kelly-Hayes M, Wolf PA, Kreger BE, Kannel WB. The effects of specific medical conditions on the functional limitations of elders in the Framingham Study. Am J Public Health. 1994;84(3):351-58.

[PMID: 8129049$]$

4. Walsh M, Woodhouse LJ, Thomas SG, Finch E. Physical impairments and functional limitations: a comparison of individuals 1 year after total knee arthroplasty with control subjects. Phys Ther. 1998;78(3):248-58. [PMID: 9520970]

5. Mancuso CA, Sculco TP, Wickiewicz TL, Jones EC, Robbins L, Warren RF, Williams-Russo P. Patients' expectations of knee surgery. J Bone Joint Surg Am. 2001;83-A(7):1005-12. [PMID: 11451969]

6. Noble PC, Conditt MA, Cook KF, Mathis KB. The John Insall Award: Patient expectations affect satisfaction with total knee arthroplasty. Clin Orthop Relat Res. 2006;452: 35-43. [PMID: 16967035]

7. Trousdale RT, McGrory BJ, Berry DJ, Becker MW, Harmsen WS. Patients' concerns prior to undergoing total hip and total knee arthroplasty. Mayo Clin Proc. 1999;74(10): 978-82. [PMID: 10918863]

8. Foley SJ, Lord SR, Srikanth V, Cooley H, Jones G. Falls risk is associated with pain and dysfunction but not radiographic osteoarthritis in older adults: Tasmanian Older Adult Cohort study. Osteoarthr Cart. 2006;14(6):533-39. [PMID: 16460970]

9. Hurley MV, Rees J, Newham DJ. Quadriceps function, proprioceptive acuity and functional performance in healthy young, middle-aged, and elderly subjects. Age Aging. 1998;27(1):55-62. [PMID: 9504367]

10. Nguyen ND, Pongchaiyakul C, Center JR, Eisman JA, Nguyen TV. Identification of high-risk individuals for hip fracture: a 14-year prospective study. J Bone Miner Res. 2005;20(11):1921-28. [PMID: 16234964]

11. Scott A. Falls on stairways-Literature review, Report Number HSL/2005/10. Harpur Hill (England): Health \& Safety Laboratory; 2005. 
12. National Safety Council. Accident Facts. Chicago (IL): National Safety Council; 1985.

13. Templer J, Archea J, Cohen HH. Study of factors associated with risk of work-related stairway falls. J Safety Res. 1985;16:183-96.

14. Nagata H. Occupational accidents while walking on stairs. Safety Sci. 1991;14:199-211.

15. Guide to Physical Therapist Practice. Alexandria (VA): American Physical Therapy Association; 1999. p. 1-1-1-15.

16. Bohannon RW, Brennan P, Pescatello LS, Hasson S, Murphy M, Marschke L. Relationships between perceived limitations in stair climbing and lower limb strength, body mass index, and self-reported stair climbing activity. Top Geriatr Rehabil. 2005;21(4):350-55.

17. Corrigan D, Bohannon RW. Relationship between knee extension force and stand-up performance in communitydwelling elderly women. Arch Phys Med Rehabil. 2001; 82(12):1666-72. [PMID: 11733880]

18. Eriksrud O, Bohannon RW. Relationship of knee extension force to independence in sit-to-stand performance in patients receiving acute rehabilitation. Phys Ther. 2003; 83(6):544-51. [PMID: 12775200]

19. Janssen WG, Bussmann HB, Stam HJ. Determinants of the sit-to-stand movement: a review. Phys Ther. 2002;82(9): 866-79. [PMID: 12201801]

20. Mizner RL, Snyder-Mackler L. Altered loading during walking and sit-to-stand is affected by quadriceps weakness after total knee arthroplasty. J Orthop Res. 2005; 23(5):1083-90. [PMID: 16140191]

21. Kennedy DM, Stratford PW, Hanna SE, Wessel J, Gollish JD. Modeling early recovery of physical function following hip and knee arthroplasty. BMC Musculoskelet Disord. 2006;7:100. [PMID: 17156487]

22. Sowers M, Jannausch ML, Gross M, Karvonen-Gutierrez CA, Palmieri RM, Crutchfield M, Richards-McCullough K. Performance-based physical functioning in AfricanAmerican and Caucasian women at midlife: considering body composition, quadriceps strength, and knee osteoarthritis. Am J Epidemiol. 2006;163(10):950-58.

[PMID: 16554351]

23. Perron M, Malouin F, Moffet H. Assessing advanced locomotor recovery after total hip arthroplasty with the timed stair test. Clin Rehabil. 2003;17(7):780-86. [PMID: 14606746]

24. Mizner RL, Petterson SC, Snyder-Mackler L. Quadriceps strength and the time course of functional recovery after total knee arthroplasty. J Orthop Sports Phys Ther. 2005; 35(7):424-36. [PMID: 16108583]

25. Irrgang JJ, Snyder-Mackler L, Wainner RS, Fu FH, Harner CD. Development of a patient-reported measure of function of the knee. J Bone Joint Surg Am. 1998;80(8):1132-45. [PMID: 9730122]

26. Jones CJ, Rikli RE, Beam WC. A 30-s chair-stand test as a measure of lower body strength in community-residing older adults. Res Q Exerc Sport. 1999;70(2):113-19.

[PMID: 10380242]

27. Rikli RE, Jones CJ. Development and validation of a functional fitness test for community-residing older adults. J Aging Phys Act. 1999;7(2):129-61.

28. Stratford PW, Kennedy DM. Performance measures were necessary to obtain a complete picture of osteoarthritic patients. J Clin Epidemiol. 2006;59(2):160-67.

[PMID: 16426951]

29. Ikezoe $T$. The relationship between quadriceps strength and balance to fall of elderly admitted to a nursing home. J Phys Ther Sci. 2003;15(2):75-79.

30. Hilding MB, Lanshammar H, Ryd L. Knee joint loading and tibial component loosening. RSA and gait analysis in 45 osteoarthritic patients before and after TKA. J Bone Joint Surg Br. 1996;78(1):66-73. [PMID: 8898130$]$

31. Kuster MS, Stachowiak GW. Factors affecting polyethylene wear in total knee arthroplasty. Orthopedics. 2002; 25(2 Suppl):S235-42. [PMID: 11866159]

32. Kaufman KR, Hughes C, Morrey BF, Morrey M, An KN. Gait characteristics of patients with knee osteoarthritis. J Biomech. 2001;34(7):907-15. [PMID: 11410174]

33. Lindstedt SL, Reich TE, Keim P, LaStayo PC. Do muscles function as adaptable locomotor springs? J Exp Biol. 2002; 205(Pt 15):2211-16. [PMID: 12110655$]$

34. Mian OS, Thom JM, Narici MV, Baltzopoulos V. Kinematics of stair descent in young and older adults and the impact of exercise training. Gait Posture. 2007;25(1):9-17. [PMID: 16481170]

35. Krebs DE, Scarborough DM, McGibbon CA. Functional vs. strength training in disabled elderly outpatients. Am J Phys Med Rehabil. 2007;86(2):93-103. [PMID: 17251692]

36. Topp R, Woolley S, Hornyak J, Khuder S, Kahaleh B. The effect of dynamic versus isometric resistance training on pain and functioning among adults with osteoarthritis of the knee. Arch Phys Med Rehabil. 2002;83(9):1187-95. [PMID: 12235596]

37. LaStayo PC, Ewy GA, Pierotti DD, Johns RK, Lindstedt SL. The positive effects of negative work: increased muscle strength and decreased fall risk in a frail elderly population. J Gerontol A Biol Sci Med Sci. 2003;58(5):M419-24. [PMID: 12730250]

38. Bookwala J, Harralson TL, Parmelee PA. Effects of pain on functioning and well-being in older adults with osteoarthritis of the knee. Psychol Aging. 2003;18(4):844-50. [PMID: 14692869]

39. Cooper JK, Kohlmann T. Factors associated with health status of older Americans. Age Aging 2001;30(6):495-501. [PMID: 11742779]

Submitted for publication November 21, 2006. Accepted in revised form May 9, 2007. 